$\xi=$ 줄

\title{
Role of sea buckthorn oil in management of chronic periodontitis: follow-up study
}

\author{
Anamika Sharma ${ }^{1}$, ${ }^{*}$ Shatakshi Sharma ${ }^{2}$, Shivi Khattri ${ }^{3}$, Harshita Garg ${ }^{2}$ \\ ${ }^{1}$ Professor and Head, Swami Vivekanand Subharti University, Subharti Dental College, Meerut \\ ${ }^{2}$ Postgraduate Student, Swami Vivekanand Subharti University, Subharti Dental College, Meerut \\ ${ }^{3}$ Senior Lecturer, Swami Vivekanand Subharti University,Subharti Dental College, Meerut \\ *Corresponding author E-mail: dr.shatakshisharma@gmail.com
}

\begin{abstract}
Periodontitis is an inflammatory condition resulting in loss of periodontal ligament and alveolar bone. Nonsurgical therapy remains the cornerstone of periodontal treatment. For sustained plaque control it plays an important role in achieving successful long-term results for the care of Chronic Periodontitis subjects. Proper maintenance and patient hygiene plays a vital role in suppression of re-colonization of micro-organism. Many adjunctive treatment modalities along with mechanical debridement have been clinically used and investigated for their efficacy. Systemic antioxidants in conjunction with scaling and root planing can offer additional effects and can be used as an adjunctive treatment. Patients with periodontal disease display increased PMN number and activity, resulting in high degree of free radical release culminating in heightened oxidative damage to gingival tissues, periodontal ligament and alveolar bone. Damage mediated by free radicals can be mitigated by "antioxidant defense system ".Sea buckthorn oil is an omega-7 fatty acid antioxidant which has unique botanical and nutritional properties thereby benefiting mucous membrane by reducing inflammation, improving wound healing and showing excellent antibacterial property. In this research patients were prescribed systemic antioxidant after the phase 1 therapy ie scaling and root planing to observe its effects on the various clinical parameters.
\end{abstract}

Keywords: Antioxidants; Periodontitis; Sea Buckthorn Berry

\section{Introduction}

The biochemical reactions which take place within the organelles and cells of the body are the main driving force which helps to sustain human life (Majeed A. 2005) and the free radicals that are produced. These free radicals are reactive species as they have a single unpaired electron in an outer orbit (Riley PA. 1994) are the main by-products formed in the cells of various micro-organism, and can initiate autocatalytic reactions as they react themselves to propagate the chain of damage (Cadenas 1989). At the same time there are certain endogenous and exogenous antioxidants which act as free radical scavengers that can be either is produced by the body or externally be supplied through various other sources thus enhancing the immune defence mechanism (Valko et al. 2006).

Nature itself act as a chemist as variety of antioxidants factors are found in plants and berries, such as alpha-tocopherol, ascorbate, carotenoids, and zinc, plant based medicines that may contain flavonoids, polyphenols, and flavoproteins. Further, some plants or specific combinations of herbs in formulations may act as antioxidants by exerting superoxide scavenging activity or by activating superoxide dismutase activity in various tissue sites which neutralises free radicals activity (Sawant 2009, Alok 2014) According to the records, Chinese were the first to use sea buckthorn oil (SBO) (fig.1) as a drug and it was then in 1977 that this plant was formally listed in the Chinese pharmacopoeia. Seabuckthorn (Hippophae rhamnoides L. Family Elaeagnaceae) are small orange yellow-to-red coloured fruits which are found on high altitude of 2500- $4300 \mathrm{~m}$ in several Asian and European countries including
India, China, Nepal, Britain, Germany, France, Finland, and Russia. In India it is found mainly on high altitudes of Ladakh, LahulSpiti, parts of Chamba and upper Kinnaur district of Himachal Pradesh, Sikkim and Arunachal Pradesh (Rousi 1971).

This plant is also referred many a times as a 'wonder plant' (Li \& Schroeder 1999) as the seed oil contains high amounts of vitamins A, E, K, carotenoids, phytosterols. SBO pulp is an excellent source of omega 7 (palmitic acid, palmitoleic acid), while the seed oil has an high content of omega 3 ( $\alpha$-lenolenic acid), omega 6 (linoleic acid), omega 9(oleic acid) fatty acids. The fatty acid content of the oil acts as epidermal barrier system which stabilizes cell membrane structure (Yang et al. 2000, Alam 2004, Ze-Li et al. 2003).

As an immunity enhancer, it maintains the immune system and keeps the supervisory role of the system normal and healthy (Alam 2004). Studies (Yang et al. 2000, Liu et al. 1980) of SBO have suggested its usefulness in treating damage which is caused by radiation, burns, eye, skin diseases, cardiovascular diseases, oral inflammation, mucous injuries and gastric ulcers.

The oil has an anti-oxidative, antimicrobial, immuno-modulatory, cytoprotective, liver fibrosis and tissue regenerative properties (Ze-Li et al. 2003, Geetha et al. 2002, Negi et al. 2005).

Chronic periodontitis also referred as "alveolar pyorrhoea" is inflammatory conditions of the gingiva (commonly known as gums) involving alveolar bone and other supporting structures of the teeth which can lead to their progressive destruction and therefore can cause pocket formation, tooth mobility etc. 
Since the literature on usage of SBO on periodontitis are very few, therefore this study aims to assess the effect of sea buckthorn oil as an adjunct in management of chronic periodontitis subjects.

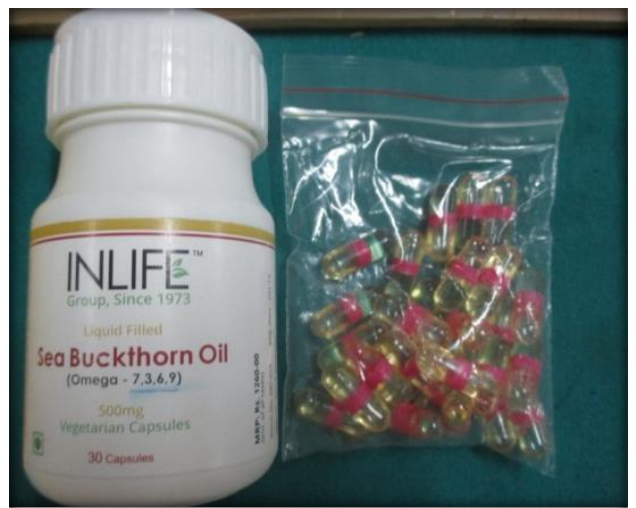

Fig. 1: SBO Capsules.

\section{Materials and methods}

\subsection{Grouping and study design}

Patient recruitment and data collection was done in the Department of Periodontology, Swami Vivekananda Subharti University, Meerut, and Uttar Pradesh. An ethical clearance was obtained from the institutional review board of the university. The study population included 30 subjects (both males \& females) with chronic periodontitis who were selected from the outpatient department of Subharti Dental College and Hospital, of the same university. All the patients were explained about the additional benefits of systemically delivered antioxidants in reducing periodontitis. Those patients who were convinced for the antioxidant adjunctive therapy were given SBO capsules were allotted to test group (group A) and others who subjected to SRP alone were allotted to control group (group B).

\subsection{Inclusion criteria}

The following inclusion criteria were used. Patients with: 1) age ranging from 18 to 35 years of age 2) untreated periodontitis involving $>30 \%$ of the sites 3) Clinical and Radiographic signs of moderate (clinical attachment loss (CAL) of 3-4 mm) chronic periodontitis (Armitage GC 1999). 4) Probing pocket depth (PPD) of $3-5 \mathrm{~mm} \mathrm{5).} \mathrm{All} \mathrm{patients} \mathrm{who} \mathrm{were} \mathrm{willing} \mathrm{to} \mathrm{participate} \mathrm{and}$ agreed to be available at any time as required for participation, and therefore agreed themselves to abstain from using anti-microbial mouth rinse during the study except for those explicitly prescribed.

\subsection{Exclusion criteria}

Patients with: 1) aggressive periodontitis 2) confirmed or assumed allergies or hypersensitive skin reactions, 3) systemic diseases/genetic disorders/ HIV/AIDS 4) patients taking systemic medication affecting the periodontium e.g. phenytoin, nifedipine and or steroid drugs, 5) Patients who had undergone professional periodontal therapy during the past 6 months prior to baseline, 6) patients requiring antibiotic coverage for any other dental treatment, 7) pregnant or lactating females, 8) patients with adverse habits such as smoking, drinking alcohol were all excluded from the study.

\subsection{Informed consent}

All the subjects who matched our inclusion criteria were clearly explained about the study. The final decision of their enrolment in the study was solely left on the subjects. An informed consent was duly signed by the subject who agreed to be the part of the study.

\subsection{Clinical parameters}

Full mouth periodontal parameters were recorded at the baseline and during follow up appointments; which included the following: 1) Plaque Index (PI) (Silness.P \& Loe H 1964) 2) Gingival Index (GI) (Loe H \& Silness P 1963), 3). Bleeding on Probing (BOP) (Ainamo \& Bay 1975), 4) CAL, 5) PPD

\section{Periodontal therapy and intervention}

Patients were subjected to meticulous scaling and root planing by ultrasonic scalers, manual scalers and curettes. The patients who were allocated in group A were given sea buckthorn capsules (Inlife ${ }^{\mathrm{TM}}$, Inlife health Care Pvt. Limited) 500mg capsules for 21 days and were given a telephonic reminder each day for the intake of these capsules whereas patients of group B were subjected to SRP only. Patients of both the groups were recalled after 21 days for evaluation.

\section{Statistical analysis and results}

The data obtained was subjected to statistical analysis.

Table 1 and 2 represent the periodontal parameters of group A \& $\mathrm{B}$ respectively. In both the groups, statistically significant improvement was seen in the periodontal parameters during the follow up (p-values of PI $<0.001$, BOP $<0.001$, GI $<0.001$, PPD $<0.002$, CAL $<0.001)$.

\begin{tabular}{|c|c|c|c|c|c|c|c|c|c|c|}
\hline & \multicolumn{2}{|c|}{ Plaque index } & \multicolumn{2}{|c|}{ Bleeding on probing } & \multicolumn{2}{|c|}{ Gingival index } & \multicolumn{2}{|c|}{ Pocket probing depth } & \multicolumn{2}{|c|}{$\begin{array}{l}\text { Clinical attachment } \\
\text { level }\end{array}$} \\
\hline & Pre & $\begin{array}{l}\text { At } 3 \\
\text { weeks }\end{array}$ & Pre & $\begin{array}{l}\text { At } 3 \\
\text { weeks }\end{array}$ & Pre & $\begin{array}{l}\text { At } 3 \\
\text { weeks }\end{array}$ & Pre & $\begin{array}{l}\text { At } 3 \\
\text { weeks }\end{array}$ & Pre & $\begin{array}{l}\text { At } 3 \\
\text { weeks }\end{array}$ \\
\hline Mean & 2.38 & 1.10 & 86.54 & 30.26 & 2.41 & 1.05 & 3.68 & 2.23 & 4.39 & 2.69 \\
\hline $\mathrm{SD}$ & 0.27 & 0.19 & 13.93 & 8.40 & 0.28 & 0.21 & 0.76 & 0.45 & 1.10 & 0.57 \\
\hline Min & 2.00 & 0.83 & 60.90 & 19.35 & 2.10 & 0.83 & 3.01 & 1.30 & 2.45 & 1.94 \\
\hline $\operatorname{Max}$ & 2.80 & 1.50 & 100.00 & 49.16 & 2.90 & 1.50 & 5.00 & 2.84 & 6.20 & 3.79 \\
\hline p-value & $<0.001$ & & $<0.001$ & & $<0.001$ & & $<0.001$ & & $<.002$ & \\
\hline
\end{tabular}

Table 2: Comparison of Periodontal Parameters at Baseline and Follow-Up at 3 Weeks in Group B

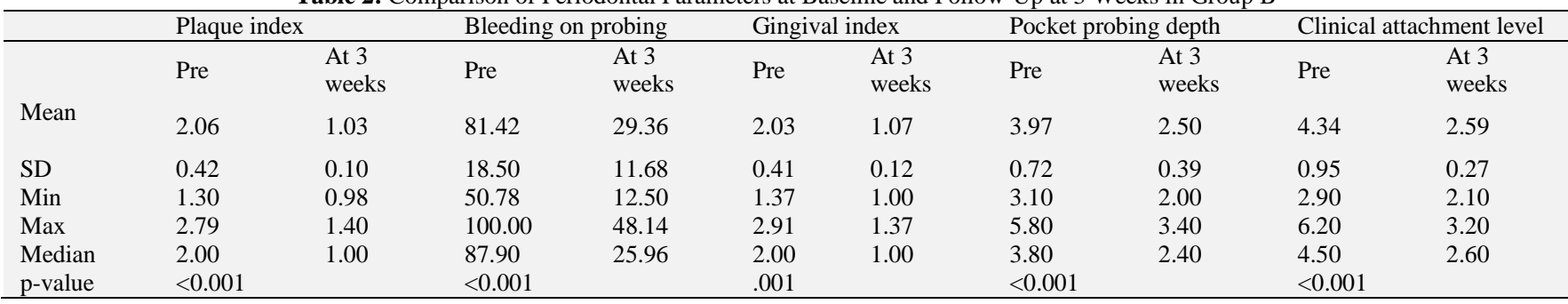


The main objective of this study was to examine the role of SBO capsules in management of chronic periodontitis subjects. Intergroup comparison is represented in Table 3 . There seems to be no statistically significant difference among the two groups. However a significant difference was found in PPD $(\mathrm{p}$-value $=0.0174)$.

Table 2: Periodontal Parameters of Group A and B at 3 Weeks

\begin{tabular}{lll}
\hline & Group A & Group B \\
\hline & Mean \pm S.D at 3 weeks & Mean \pm S.D at 3 weeks \\
Plaque Index & $1.10 \pm 0.19$ & $1.03 \pm 0.10$ \\
Bleeding On Probing & $30.26 \pm 8.40$ & $29 \pm 11.68$ \\
Gingival Index & $1.05 \pm 0.21$ & $1.07 \pm 0.21$ \\
Pocket Probing Depth & $2.23 \pm 0.45$ & 0.211 \\
Clinical Attachment Level & $2.69 \pm 0.57$ & 0.789 \\
\hline
\end{tabular}

The graphical representations of the periodontal parameters at follow-up are shown in fig 2-6.

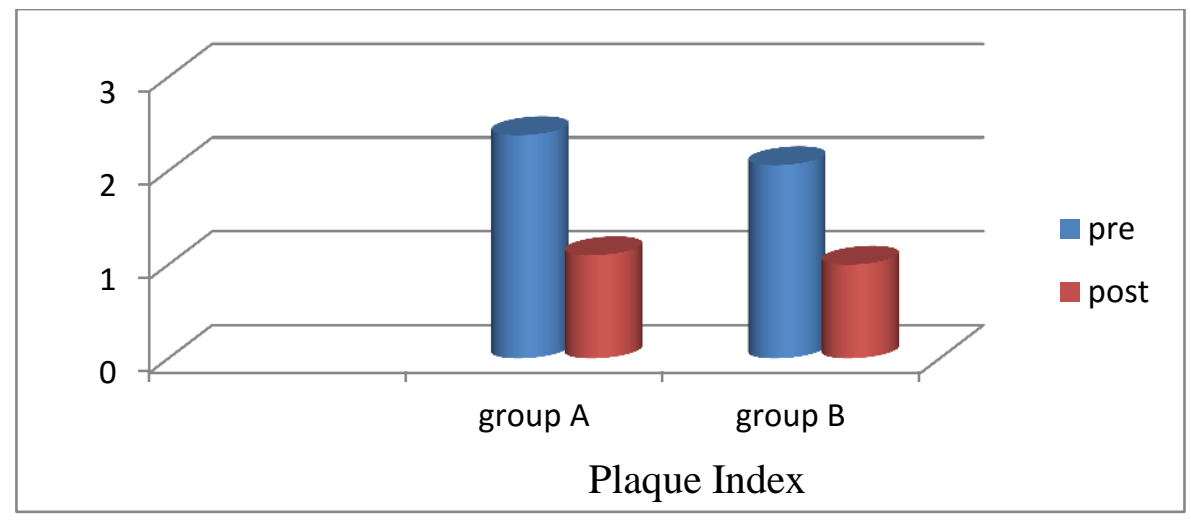

Fig. 2: Shows No Statistical Significant Difference between Group A and B after the Treatment.

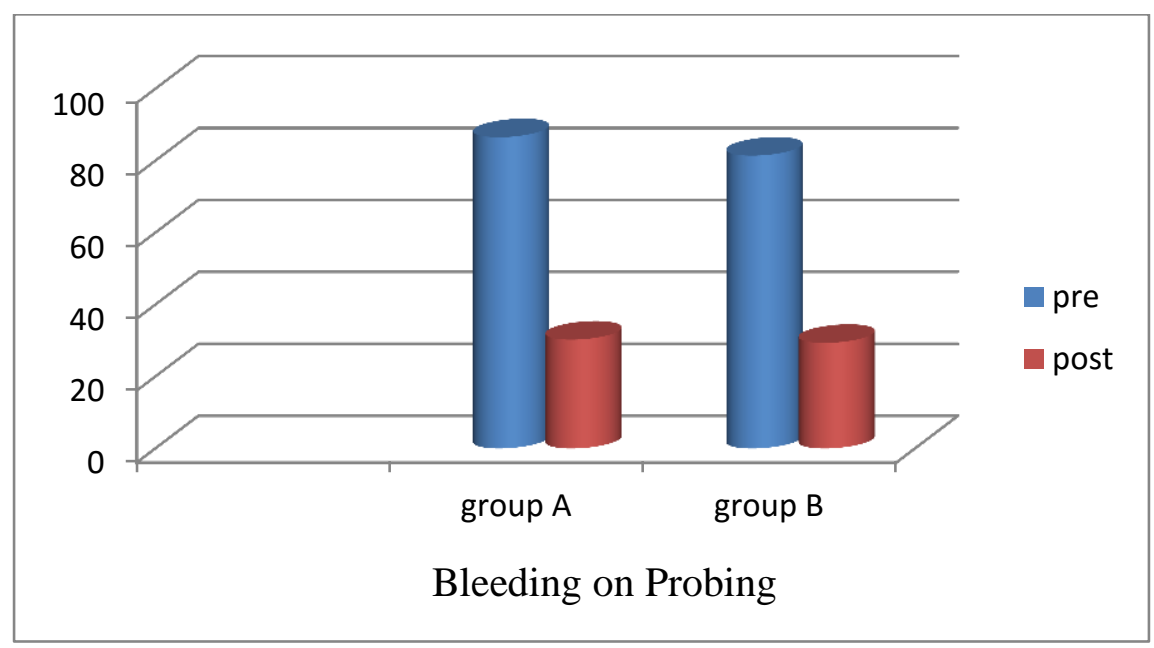

Fig. 3: Shows No Significant Difference between Group A and B after the Treatment

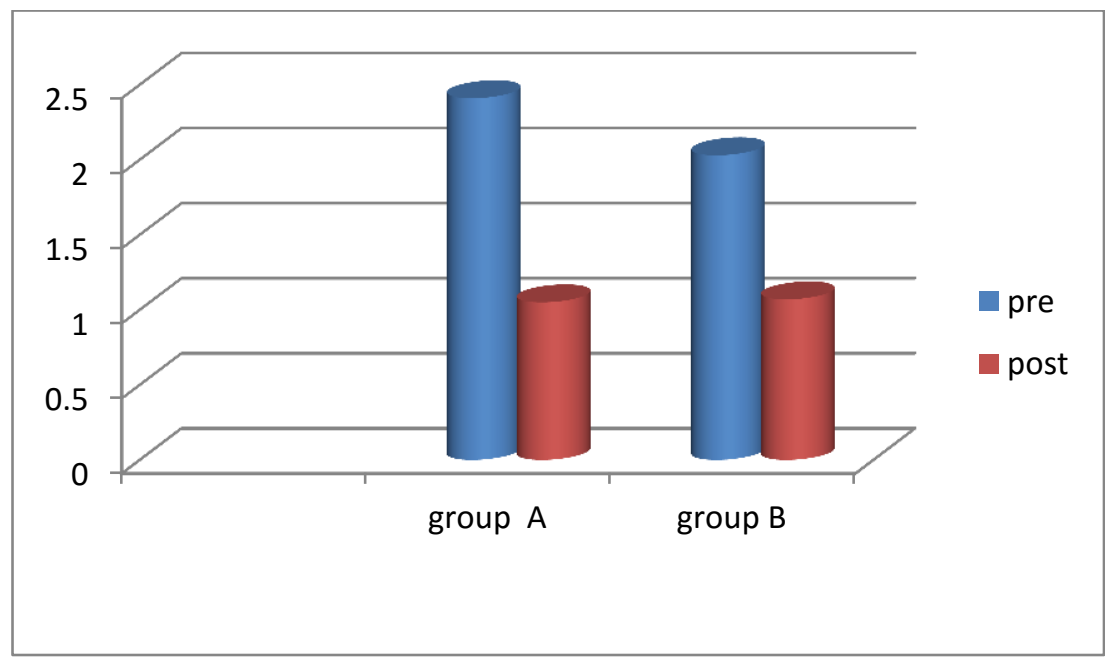

Fig. 4: Shows No Significant Difference between Group A and B after the Treatment. 


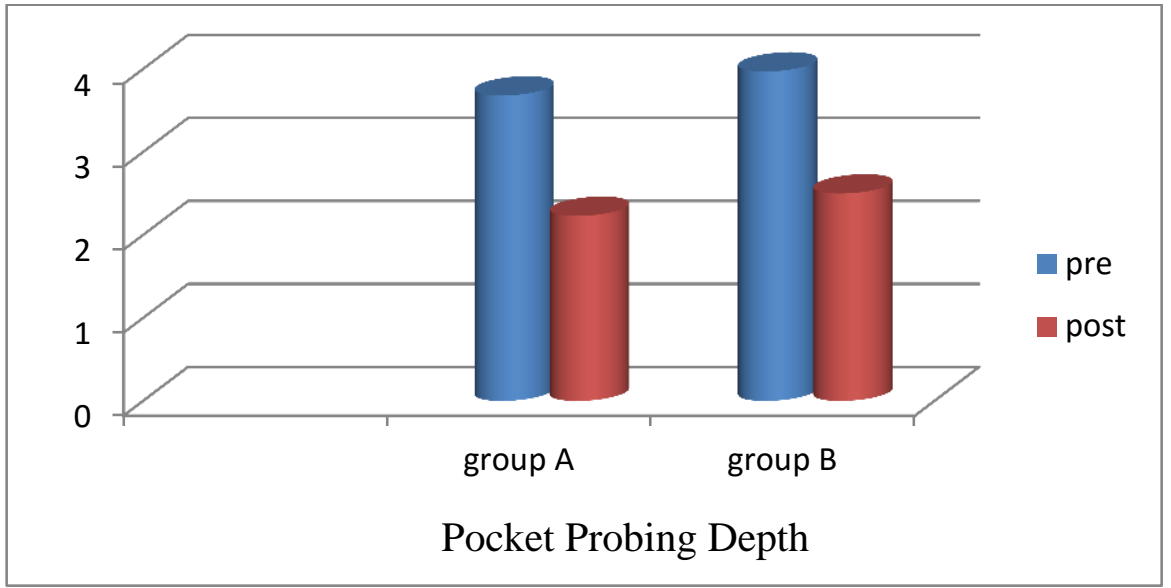

Fig. 5: Showing Statistical Difference between Group A and B after the Treatment Suggesting some Regenerative Potential of SBO.

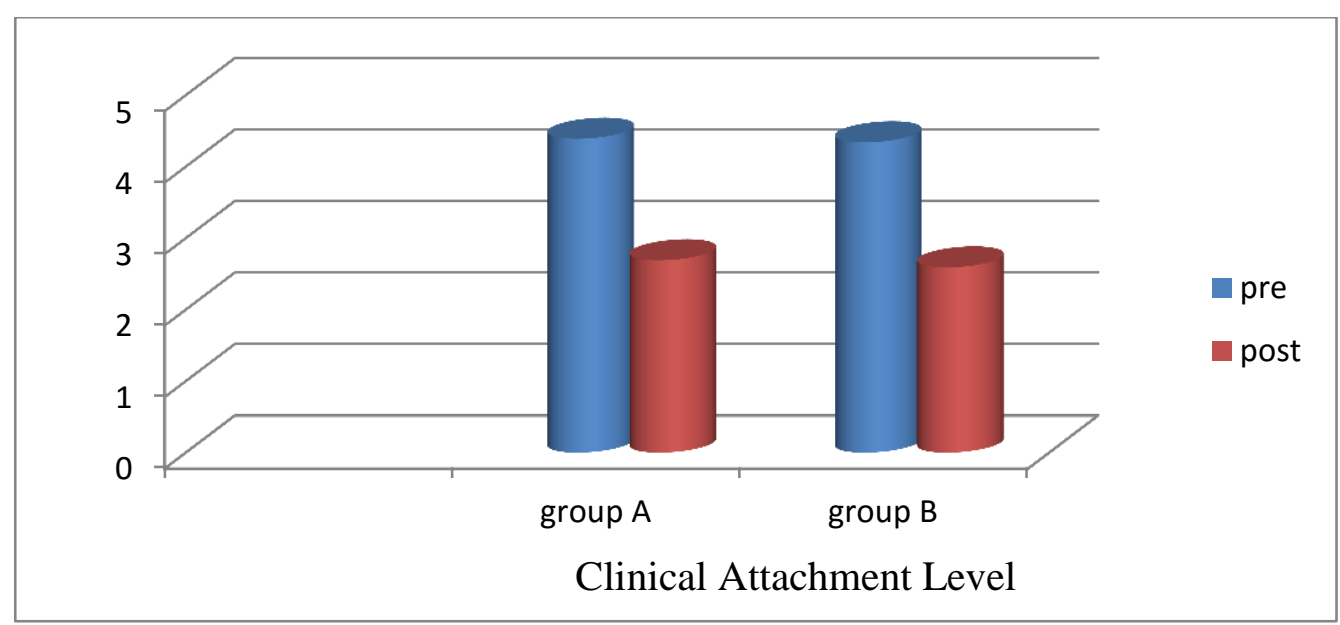

Fig. 6: Shows No Significant Difference between Group A and B after the Treatment.

\section{Discussion}

Sea buckthorn berry is known to be effective in treating wounds, inflammation, mucous-membrane-related disorders. Scientists have carried out extensive research on sea buckthorn which has resulted in an improved understanding of the health effects and the chemical composition of the berry.

In a study (Li et al. 1989), SBO was topically used to treat ulcerative stomatitis in children of age 4 months to 12 years which resulted in significant improvement after two days. It has also proved to be effective against ulcerative stomatitis in leukemic patients (Le Bell et al. 2002).

Carotenoids and vitamin $\mathrm{E}$ in the oils have found to be responsible for the clear tissue-regenerative effects (Krichkovskaya et al. 1992).

Dry mouth, which is a symptom of salivary gland dysfunction, provokes unpleasant oral symptoms such as burning mouth, difficulty in speaking, chewing and swallowing in almost $40 \%$ of adults mainly women and the elderly. It was found that on oral treatment with SBO (a mixture of pulp oil and seed oil) capsules ( $5 \mathrm{~g}$ oil per day) for four weeks, symptoms of dry mouth effectively improved. The general conditions of mouth mucosa have shown remarkable improvements (Tsybikova et al. 1992).

To the best of the author's knowledge this is the first clinical research to evaluate the effects of systemically delivered SBO on the clinical parameters as well as on the inflammation along the gingival margin.

During follow up, there was a marked reduction in all the clinical parameters such as PI, GI, BOP, PPD, and CAL in both the groups, on intra-oral examination it was also found that there were no signs of inflammation redness, bleeding on probing had disappeared along the gingival margin. However on comparing the control and test group respectively, the authors did not found any significant difference between the two groups however there was a slight significant reduction seen during probing the pocket, the reason for this can be attributed to the regenerating effects of SBO that had previously been reported in many literature (Krichkovskaya et al. 1992).

The authors conclude by saying that SBO is a wonder plant but its effects in the fields of dentistry still need further researches. However, further clinical studies with more sample size can be done to confirm our results.

\section{Acknowledgement}

I would like to thank the almighty, my family members, my newly born niece and my teachers for their constant support throughout this study.

\section{References}

[1] Majeed A, Aylin P (2005). The ageing population of the United Kingdomand cardiovascular disease. BMJ,331:1362.

[2] Riley PA (1994). Free radicals in biology: oxidative stress and effects of ionizing radiation. Int J Rad Biol, 65:27-33.

[3] Cadenas E (1989). Biochemistry of oxygen toxicity. Ann Rev Biochem,58:79-110.

[4] Valko M, Rhodes CJ, Moncol J, Izakovic M et al (2006). Free radicals, metabolism and antioxidants in oxidative stress- induced cancer.Chem Biol Interact; 160:38-40.

[5] Sawant O, Kadam VJ, Ghosh R. (2009) In vitro free radical scavenging and antioxidant act activity of Adiantum lunulatum. J Herbal Med Toxicol; 3(2): 39-44.

[6] Alok S, Jain SK, Verma A, Kumar M, Mahor A, Sabharwal M Herbal antioxidant in clinical practice: A review. Asian Pac $J$ Trop Biomed. 2014 Jan;4(1):78-84 
[7] Li T. and Schroeder B. (1999). A grower's guide to sea buckthorn. Agriculture and Agri-Food Canada, PFRA Shelter Belt Centre. Indian Head, SK.

[8] Rousi A (1971). The genus Hippophae L. A taxonomic study. Ann. Bot. Fennici 8, 177-227.

[9] Yang B., Kalimo, K O., Tahvonen, R L., Mattila, L M., Katajisto J K, Kallio H P; (2000). Effect of Dietary supplementation with sea buckthorn (Hippophaë rhamnoides) seed and pulp oils on the fatty acid composition of skin glycerophospholipids of patients with atopic dermatitis. J. Nutr. Biochem. 11(6), 338-340..

[10] Alam Z (2004) Chemical and nutritional constituents of seabuckthorn juice. Pak. J. Nutr., 3, 99-106.

[11] Ze-Li Gao, Xiao-Hong Gu, Feng-Tao Cheng, and Fo-Hu Jiang (2003). Effect of seabuckthorn on liver fibrosis: a clinical study. World J Gastroenterol. 9, 1615-1617..

[12] Liu, B. Wu, Z. Liu, W (1980). Preliminary observation on curing effects of Sea-buckthorn fruit juice for high blood cholesterol and coronary heart disease. Acta Academiae Medicinae Sichua. 11(3), 178-182.

[13] Geetha, S. Sai Ram, M. Singh, V. Ilavazhagan, G. Sawhney, R.C (2002). Antioxidant and immunomodulatory properties of seabuckthorn (Hippophae rhamnoides) - An in vitro study. J.Ethnopharmacol. 79, 373-378.

[14] Negi P, Chauhan A, Sadia G, Rohinishree Y, Ramteke R (2005) Antioxidant and antibacterial activities of various seabuckthorn (Hippophae rhamnoides L.) seed extracts. Food Chem. 92,119-124..

[15] Armitge GC (1999) Development of a classification system for periodontal diseases and conditions, Ann Periodontol 4:1.

[16] Loe H \& Silness J (1963). Periodontal disease in pregnancy. ActaOdontol Scand; 21: 533-551. 93

[17] Silness P \& Loe H (1964). Periodontal disease in pregnancy. ActaOdontol Scand.; 22:121-135..

[18] Li Z.M., Deng Z.C., An H.L., Zhang W.L., Zhang Z.F., Ge L., Sun S.X. (1989); Hippophä̈ (4) 37-40.

[19] Le Bell A.M., Söderling E., Rantanen I., Yang B., Kallio H. (2002); Poster at the Eightieth General Session \& Exhibition of International Association for Dental Research (IADR), March 6-9, San Diego, USA.

[20] .Krichkovskaya L.V, Dementij R.N., Zyabchenkova A.K. (1992)"Research on the antioxidative property of sea buckthorn oil and Akeol" in: Scientific Communication, WugongAgricultural Research Center, Shaanxi Province ed. Advances in the Biochemical and Pharmacological Research on Sea Buckthorn;Wugong Publishing House, Wugong, Shannxi Province, China, pp.141-142.

[21] Tsybikova D.T.S., Feddtdvskaya N.N,Darzhapova G.Z.H, Nikolaev S.M., Bolotova M.N. (1992) "Chemical and pharmacological characteristics of fat-soluble compounds in sea buckthorn press residue" in: Scientific Communication, Wugong Agricultural Research Center, Shaanxi Province ed. Advances in the Biochemical and Pharmacological Research on Sea Buckthorn; Wugong Publishing House, Wugong, Shannxi Province, China,pp.141-142. 